\title{
VALIDATION OF THE BRAZILIAN VERSION OF GUY'S NEUROLOGICAL DISABILITY SCALE
}

\author{
Carolina R. Araujo', Luciano M. Simão², Mariana I. Ybarra³, \\ Natasha V.M.G. Faria ${ }^{4}$, Caroline M. Botelho ${ }^{5}$, Marcos A. Moreira ${ }^{5}$, \\ Antônio L. Teixeira ${ }^{6}$, Marco A. Lana-Peixoto ${ }^{7}$
}

\begin{abstract}
The Guy's neurological disability scale (GNDS) has recently been introduced as a new measure of disability in multiple sclerosis. It is patient-oriented, multidimensional, and not biased towards any particular disability. The purpose of the present study was to validate the Brazilian version of the GNDS. The adaptation of the scale was based on the translation/back-translation methodology. Sixty-two patients with clinically definite multiple sclerosis (CDMS) according to Poser's criteria were recruited for this study. GNDS was administered individually to each subject. The EDSS and the ambulation index (AI) scores were assigned by a neurologist. The intraclass correlation coefficient and the Cronbach's $\alpha$ values of the Brazilian version of GNDS ( 0.94 and 0.83 , respectively) were comparable to the original one $(0.98$ and 0.79 , respectively). Furthermore, the factor analysis of the Brazilian version of GNDS suggested, as the original article, a four-factor solution which accounted for $68.8 \%$ of the total variance. The Brazilian version of GNDS was found to be clinically relevant as it correlated significantly with the EDSS and Al. In conclusion, the Brazilian version of GNDS can be considered an important tool to evaluate the disability in MS patients, with clinical usefulness and psychometrics soundness.
\end{abstract}

KEY WORDS: multiple sclerosis, Guy's neurological disability scale, expanded disability status scale (EDSS), disability.

\begin{abstract}
Validação da versão brasileira da escala de incapacidade neurológica de Guy
RESUMO - A Guy's neurological disability scale (GNDS) é uma escala de incapacidade criada recentemente, orientada para o paciente, multidimensional, e que não privilegia nenhum tipo específico de incapacidade. O objetivo deste estudo é validar a GNDS para a língua portuguesa. A adaptação da escala foi feita através do método de tradução e re-tradução. Sessenta e dois pacientes com esclerose múltipla (EM) clinicamente definida de acordo com os critérios de Poser participaram deste estudo. A GNDS foi aplicada individualmente em cada paciente. O EDSS e o índice ambulatorial (IA) foram determinados por neurologista. A correlação intra-classe e o valor de Cronbach's $\alpha$ da versão brasileira da GNDS (0.94 e 0.83, respectivamente) foram comparáveis aos do artigo original (0.98 e 0.79, respectivamente). Como no artigo original, a análise fatorial da versão brasileira da GNDS sugeriu uma solução de quatro fatores que explicaria $68.8 \%$ da variação total. A versão brasileira da GNDS mostrou-se clinicamente relevante uma vez que se correlacionou com o EDSS e o IA. Em conclusão, a versão brasileira da GNDS pode ser considerada como um importante instrumento de avaliação incapacidade na EM com significado clínico e relevância psicométrica.
\end{abstract}

PALAVRAS-CHAVE: esclerose múltipla, escala de incapacidade neurológica de Guy, EDSS, incapacidade.

Multiple sclerosis (MS) is a chronic immune-mediated, inflammatory demyelinating disease of the central nervous system, characterized by progressive clinical course leading to physical disability. Disability, according to the World Health Organization disablement model, is thought to be the main disease consequence which has a direct and practical rele- vance to patients as it determines their ability to perform their various daily activities ${ }^{1}$. Traditionally the expanded disability status scale (EDSS) has been used as the primary outcome measure for neurological impairment and disability in $\mathrm{MS}^{2}$. The EDSS is based on the evaluation by a neurologist of eight functional systems (visual, brainstem, pyramidal, sensory, cere-

Centro de Investigação em Esclerose Múltipla de Minas Gerais (CIEM MINAS), Departamento de Oftalmologia da Faculdade de Medicina da Universidade Federal de Minas Gerais, Belo Horizonte MG, Brasil (FMUFMG): ${ }^{1}$ Post-Graduate Medical Student; ${ }^{2}$ Ophthalmologist; ${ }^{3}$ Psychiatrist; ${ }^{4}$ Physiotherapy Student; ${ }^{5}$ Neurologist; ${ }^{6}$ Associate Professor of Neurology; ${ }^{7}$ Associate Professor of Neurology and Ophthalmology.

Received 1 December 2006. Accepted 26 March 2007. 
bellar, bowel/bladder, cerebral and 'others') and the patient's ability to walk. Its major limitation is its bias related to locomotor function ${ }^{2-4}$.

The Guy's neurological disability scale (GNDS) has recently being introduced as a new measure of disability, based mainly on patient self-report ${ }^{5}$. It is patient-orientated, multidimensional, and not biased towards any particular disability. The GNDS was devised to be a simple, user-friendly clinical disability scale capable of assessing the whole range of disabilities which can be encountered in the course of $\mathrm{MS}^{5}$. In the last few years, many MS-specific scales have being translated, validated and standardized into the Portuguese language. Two independent groups developed the Brazilian version of the multiple sclerosis functional composite measure (MSFC), an instrument that assesses motor functions of legs and arms/ hands besides cognitive function ${ }^{6,7}$. The MSFC is not suitable to patients with advanced disease who are unable to walk, to manipulate fine objects with their hands or to process mental arithmetics ${ }^{5}$. Recently, the functional assessment of multiple sclerosis (FAMS), a MS-specific quality of life instrument, was also translated and validated to Portuguese ${ }^{8}$. Despite these efforts, Brazilian MS investigators are still in need of a multidimensional disability scale in their native language.

We designed the present study aimed at validating a Brazilian version of the GNDS.

\section{METHOD}

Guy's neurological disability scale - The GNDS is a questionnaire driven by patient interview allowing the incorporation of patient's views of their disability in a structured manner. The questions assess the patient disability in the previous month. It is capable of providing information on 12 functional domains (cognition, mood, vision, speech, swallowing, upper limb function, lower limb function, bladder control, bowel control, sexual, fatigue and 'others'). The domains are graded according to their severity and impact on patients. Each domain score ranges from 0 (normal) to 5 (complete loss of function or maximal help required) and the total score ranges from 0 (no disability) to 60 (maximum possible disability) ${ }^{5}$.

The adaptation of the scale was based on the standard translation/back-translation methodology as previously performed by other authors ${ }^{8-10}$. Briefly, the original scale was translated into Portuguese language by two Brazilian bilingual's persons with experience with health terminology. The next step was the evaluation of the translation to ensure semantic equivalence and acceptability. Subsequently, the Portuguese version was retranslated into English and compared with the original version of the scale. Finally, after pilot testing, the translated questionnaire was administered to a sample of multiple sclerosis patients.
Subjects - Sixty-two patients with clinically definite multiple sclerosis (CDMS) according to Poser's criteria were recruited for this study. GNDS was administered individually to each subject. The EDSS and the ambulation index (AI) scores were assigned by a neurologist blinded to the GNDS score. For the interrater reliability assessment of the GNDS, 15 patients were rated independently by two clinicians. At the time of assessment, no patient had active neurological disease for at least four weeks.

Statistical analysis - The variables were processed in a database and statistical analysis carried out using the SPSS 12.0 software. To test the reliability, the internal consistency of the GNDS was assessed by Cronbach's $\alpha$ and the Spearman correlation coefficient calculation. The interrater reliability was assessed using an intraclass correlation coefficient (ICC). Furthermore the factor structure of the questionnaire was extracted by performing principal component analysis using varimax rotation. Finally, the validity of the instrument was assessed analyzing the correlation of the GNDS with EDSS and Al.

\section{RESULTS}

The descriptive findings of the sample are presented in Table 1. The sample comprised sixty-two patients with CDMS (32 men and 30 women) with ages ranging from 21 to 61 years (mean age 41.2, $S D \pm 9.5)$. The mean disease duration was 10.1 years $(S D \pm 7.9)$ and the mean formal schooling years of MS patients were $11.4(\mathrm{SD} \pm 4.8)$. There were 43 patients (69.4\%) with relapsing-remitting MS, 14 (22.6\%) with secondary progressive MS and five $(8.1 \%)$ with primary progressive MS. The EDSS ranged from 1 to 8.5 (mean 3.7, SD \pm 2.2 ), whereas the mean Al ranged from 0 to 9 (mean 1.9, SD \pm 2.3 ).

Table 1. Descriptive findings.

\begin{tabular}{llc}
\hline Gender & Male & $52 \%$ \\
& Female & $48 \%$ \\
Age (years) & Range & $21-61$ \\
& Mean (SD) & $41.2(9.5)$ \\
& Median & 41 \\
Formal & Range & $0-21$ \\
schooling years & Mean (SD) & $11.04(4.8)$ \\
& Median & 10 \\
Disease & Range & $1-30$ \\
duration & Mean (SD) & $10(7.8)$ \\
& Median & 7 \\
Clinical course & Relapsing-remitting MS & $69.4 \%$ \\
& Secondary progressive MS & $22.6 \%$ \\
& Primary progressive MS & $8.1 \%$ \\
EDSS & Range & $1-8.5$ \\
& Mean (SD) & $3.7(2.2)$ \\
Al & Range & $0-9$ \\
& Mean (SD) & $1.9(2.3)$ \\
\hline
\end{tabular}


Table 2. Spearman's correlation coefficients between individual sub-scales of the GNDS.

\begin{tabular}{|c|c|c|c|c|c|c|c|c|c|c|c|}
\hline & Cognition & Mood & Visual & Speech & Sallowing & $\begin{array}{c}\text { Upper } \\
\text { limb }\end{array}$ & $\begin{array}{c}\text { Lower } \\
\text { limb }\end{array}$ & Bladder & Bowel & Sexual & Fatigue \\
\hline Mood & 0.509 & & & & & & & & & & \\
\hline$p$ & 0.000 & & & & & & & & & & \\
\hline Visual & 0.313 & 0.324 & & & & & & & & & \\
\hline$p$ & 0.013 & 0.010 & & & & & & & & & \\
\hline Speech & -0.052 & 0.211 & 0.098 & & & & & & & & \\
\hline$p$ & 0.689 & 0.100 & 0.448 & & & & & & & & \\
\hline Sallowing & 0.161 & 0.316 & 0.223 & 0.311 & & & & & & & \\
\hline$p$ & 0.211 & 0.012 & 0.082 & 0.014 & & & & & & & \\
\hline Upper limb & 0.221 & 0.272 & 0.247 & 0.148 & 0.447 & & & & & & \\
\hline$p$ & 0.085 & 0.032 & 0.053 & 0.252 & 0.000 & & & & & & \\
\hline Lower limb & -0.016 & 0.119 & 0.177 & 0.272 & 0.356 & 0.548 & & & & & \\
\hline$p$ & 0.901 & 0.357 & 0.168 & 0.032 & 0.005 & 0.000 & & & & & \\
\hline Bladder & 0.107 & 0.059 & 0.263 & 0.049 & 0.430 & 0.362 & 0.482 & & & & \\
\hline$p$ & 0.410 & 0.648 & 0.039 & 0.708 & 0.000 & 0.004 & 0.000 & & & & \\
\hline Bowel & 0.104 & 0.133 & 0.162 & 0.109 & 0.317 & 0.240 & 0.248 & 0.575 & & & \\
\hline$p$ & 0.420 & 0.303 & 0.210 & 0.398 & 0.012 & 0.060 & 0.052 & 0.000 & & & \\
\hline Sexual & 0.162 & 0.051 & 0.247 & 0.144 & 0.216 & 0.400 & 0.418 & 0.286 & 0.182 & & \\
\hline$p$ & 0.208 & 0.696 & 0.053 & 0.266 & 0.092 & 0.001 & 0.001 & 0.024 & 0.157 & & \\
\hline Fatigue & 0.318 & 0.588 & 0.347 & 0.341 & 0.435 & 0.470 & 0.531 & 0.409 & 0.250 & 0.289 & \\
\hline$p$ & 0.012 & 0.000 & 0.006 & 0.007 & 0.000 & 0.000 & 0.000 & 0.001 & 0.050 & 0.023 & \\
\hline Others & 0.358 & 0.339 & 0.347 & 0.187 & 0.577 & 0.630 & 0.557 & 0.459 & 0.389 & 0.464 & 0.581 \\
\hline$p$ & 0.004 & 0.007 & 0.006 & 0.146 & 0.000 & 0.000 & 0.000 & 0.000 & 0.002 & 0.000 & 0.000 \\
\hline
\end{tabular}

Table 3. Reliability of the Brazilian version of GNDS versus original version.

\begin{tabular}{lcc}
\hline & Brazilian version & Original version \\
\hline ICC & 0.94 & 0.98 \\
Cronbach's $\alpha$ & 0.83 & 0.79 \\
Factor analysis & $68.8 \%$ & $58.7 \%$ \\
\hline
\end{tabular}

*Four factors.

Table 4. Factor structure of the Brazilian version of GNDS.

\begin{tabular}{ll}
\hline Factor & Component \\
\hline Motor & Upper and lower limbs, fatigue, sexual and "others" \\
Mental & Cognition, mood and visual \\
Autonomic & Bladder and bowel \\
Bulbar & Speech and swallowing \\
\hline
\end{tabular}

Table 5. Validity of the Brazilian version of GNDS versus original version.

\begin{tabular}{lcc}
\hline & Brazilian version & Original version \\
\hline EDSS & $0.56^{*}$ & $0.75^{*}$ \\
$\mathrm{Al}$ & $0.537^{*}$ & - \\
\hline $\mathrm{p}<0.01$ & &
\end{tabular}

Table 2 presents the Spearman correlation coefficients for the GNDS individual items. The ICC value for the GNDS was 0.94 and the Cronbach's $\alpha$ value was 0.83 (Table 3 ). The factor analysis suggested a four factor solution (Table 4) which accounted for $68.8 \%$ of the total variance. The first factor (motor factor) comprised upper limb, lower limb, fatigue, sexual and 'others' sub-scales; the second factor (mental factor), cognition, mood and visual subscales; the third factor (autonomic factor), bladder and bowel sub-scales; and the fourth factor (bulbar factor), speech and swallowing sub-scales. The Brazilian version of GNDS correlated with EDSS ( $r=0,56$, $p<0,01)$ and $\mathrm{Al}(r=0,54, p<0,01)$ (Table 5).

\section{DISCUSSION}

Assessment of patient's perspective of disability is a very important dimension of the clinical practice that has been neglected in previous instruments designed to study MS. The outcome measures available to assess MS impact provide a limited evaluation of the disablement process and therefore they are not adequate to provide a comprehensive appraisal of patients' health status. Accordingly, the GNDS was 
recently introduced. It is a new patient-oriented an multidimensional tool not biased toward any particular disability and designed as a simple scale which could be applied by doctors, nurses and other health care professionals alike ${ }^{5}$. The GNDS has been useful to MS researchers undertaking a variety of clinical studies. For instance, the GNDS was used to assess disability in clinical trials ${ }^{11-13}$, as well as one of the methods used to evaluate differences among MS outcome measures ${ }^{14-18}$.

The statistical properties of the Brazilian version of GNDS were similar to those of the original questionnaire ${ }^{5}$. The ICC and the Cronbach's $\alpha$ values of the Brazilian version of GNDS ( 0.94 and 0.83 , respectively) were comparable to the original one ( 0.98 and 0.79 , respectively). Furthermore, the factor analysis of the Brazilian version of GNDS suggested, as the original article, a four-factor solution which accounted for $68.8 \%$ of the total variance, whereas the original accounted for $58.7 \%$. One difference refers to the sub-scales grouped in 1 of the 4 factors. In the original study, there was a 'spinal factor' correlated with lower limb, bladder, bowel and sexual function scales. In the present study, lower and upper limbs were grouped in a 'motor factor', whereas bladder and bowel functions were grouped in the 'autonomic factor'. In both studies there were 'mental' and 'bulbar' factors. The Brazilian version of GNDS was found to be clinically relevant as it correlated significantly with EDSS and Al.

The Brazilian version of GNDS is the first MS-specific disability scale translated into and validated to Portuguese language. The present study shows that due to its clinical usefulness and psychometrics soundness the Brazilian version of GNDS can be a promising tool to evaluate disability in MS patient in Brazilian and other Portuguese speaking populations.

\section{REFERENCES}

1. World Health Organizatin. International Classification of impairments, disabilities and handcaps. Geneva: World Health Organization, 1980.

2. Kurtzke JF. Rating neurologic impairment in multiple sclerosis: an expanded disability status scale (EDSS). Neurology 1983;33:144-152.

3. Whitaker JN, Mc Farland HF, Rudge P, Reingold SC. Outcomes assessment in multiple sclerosis clinical trials: a critical analysis. Multiple Sclerosis 1995;1:37-47.

4. Hobart J, Freeman J, Thompson A. Kurtzke scales revisited: the application of psychometric methods to clinical intuition. Brain 2000;123:10271040.

5. Sharrack B, Hughes RAC. The Guy's neurological disability scale (GNDS): a new disability measure for multiple sclerosis. Multiple Sclerosis 1999;5:223-233.

6. Haase VG, Lima EP, Lacerda SS, Lana-Peixoto MA. Desenvolvimento da versão brasileira da multiple sclerosis functional composite measure (MSFC-BCTRIMS): estudo piloto. Arq Neuropsiquiatr 2004;62: 363-370.

7. Tilbery $\mathrm{CP}$, Mendes MF, Thomaz RB, et al. Padronização da multiple sclerosis functional composite measure (MSFC) na população brasileira. Arq Neuropsiquiatr 2005;63:127-132.

8. Mendes MF, Balsimelli S, Stangehaus G, Tilbery CP. Validação de escala de determinação funcional da qualidade de vida na esclerose múltipla para a língua portuguesa. Arq Neuropsiquiatr 2004;62:108-113.

9. Assumpcao FB Jr., Kuczynski E, Rego MGS, et al. Escala de avaliação da reação de retração no bebê: um estudo de validade. Arq Neuropsiquiatr 2002;60:56-60.

10. Fabbri RMA, Moreira MA, Garrido R, et al. Validação e confiabilidade da versão em língua portuguesa do confusion assessment method (CAM) para a detecção de delirium no idoso. Arq Neuropsiquiatr 2001;59:175-179.

11. Wade DT, Young CA, Chaudhuri KR, Davidson DLW. A randomized placebo controlled exploratory study of vitamin B-12, lofepramine, and L-phenylalanine (the "Cari Loder regime") in the treatment of multiple sclerosis. J Neurol Neurosurg Psychiatry 2002;73:246-249.

12. Craig J, Young CA, Ennis M, Baker G, Boggild M. A randomized controlled trial comparing rehabilitation against standart therapy in multiple sclerosis patients receiving intravenous steroid treatment. J Neurol Neurosurg Psychiatry 2003;74:1225-1230.

13. Hoogervorst ELJ, Kalkers NF, van Wilsen LML, Uitdehaag BMJ, Polman $\mathrm{CH}$. Differential treatment effect on measures of neurological exam, functional impairment and patient self-report in multiple sclerosis. Multiple Sclerosis 2001;7:335-339.

14. Hoogervorst ELJ, van Winsen LML, Eikelenboom MJ, Kalkers NF, Uitdehaag BMJ, Polman CH. Comparisons of patient self-report, neurologic examination and functional impairment in multiple sclerosis. Neurology 2001;56:934-937.

15. Hoogervorst ELJ, Eikelenboom MJ, Uitdehaag BMJ, Polman CH. One year changes in disability in multiple sclerosis: neurological examination compared with patient self report. J Neurol Neurosurg Psychiatry 2003;74:439-442.

16. Hobart JC, Riazi A, Lamping DL, Fitzpatrick R, Thompson AJ. Measuring the impact of MS on walking ability. The 12-item MS walking Scale (MSWS-12). Neurology 2003;60:31-36.

17. Kragt JJ, Hoogervorst ELJ, Uitdehaag BMJ, Polman CH. Relation between objective and subjective measures of bladder dysfunction in multiple sclerosis. Neurology 2004;63:1716-1718.

18. Groom MJ, Lincoln NB, Francis VM, Stephan TF. Assessing mood in patients with multiple sclerosis. Clin Rehab 2003;17:847-857. 